\title{
INOVAR PARA TRANSFORMAR A UNIVERSIDADE BRASILEIRA*
}

\section{Glauco Arbix \\ Flávia Consoni}

Qual o lugar das instituições de ensino superior e de pesquisa no Brasil em relação ao estímulo de geração e difusão de inovaçóes na economia e na sociedade?

Mudanças recentes efetivadas no ambiente econômico e social para tornar a economia brasileira mais amigável à inovação e à tecnologia geraram

* Os autores agradecem ao generoso apoio material e financeiro da Fundação Fulbright. As pesquisas para a realização desse artigo foram inspiradas no tema do New Century Scholars Program 2009-2010, “The University as Innovation Driver and Knowledge Center". Os autores agradecem também a Thaize Graziadio e Mariana Hangai pela pesquisa realizada, assim como ao apoio da Fapesp, do CNPq e de todos os NITs que concederam entrevistas para essa pesquisa. Agradecemos também aos valiosos comentários dos pareceristas anônimos.

Artigo recebido em 17/10/2010

Aprovado em 28/02/2011 impactos positivos na estrutura institucional das universidades, com avanços importantes nas áreas de proteção do conhecimento gerado por seus pesquisadores, nos sistemas de licenciamento de patentes e de transferência de tecnologia. Porém, em que pesem os passos positivos, ainda há um longo caminho a ser trilhado. A universidade brasileira permanece insulada e carece de canais de ligação capazes de viabilizar a estreita sintonia c om os esforços que faz o país para se desenvolver. A realização desse debate, muitas vezes tomado falsamente como um ataque à autonomia universitária, é cada vez mais urgente. A universidade, no mundo todo, vive uma segunda revolução acadêmica. Ensino e pesquisa combinam-se agora com forte atuação de transferência de conhecimento para a sociedade. No Brasil, é urgente a necessidde de se ampliar a sinergia e os fluxos de conhecimento entre universidade e sociedade, determinantes para a absorção, a aprendizagem e a geração de inovação e tecnologia. 
Nosso ponto de partida é que os processos de inovação em países emergentes possuem características peculiares e distintas da inovação que ocorre em países avançados. Isso se deve principalmente à maior distância da fronteira do conhecimento em que atuam majoritariamente as principais instituições que respondem pelos processos inovadores, em especial as empresas privadas. De um modo geral, os países desenvolvidos estão capacitados para investir em inovações que determinam tendências e rotas tecnológicas e, por isso mesmo, se caracterizam como criadores de "novidades para o mercado mundial". A estrutura de sua economia e a expertise de suas empresas baseiam-se em conhecimento novo, seja no uso de tecnologias orientadas para a manutenção de sua posição avançada na economia mundial, seja nos processos de ampliação de sua liderança no concerto das naçôes.

Diferentemente, os países em desenvolvimento, em quase todas as áreas da economia, buscam equiparar-se (catch up) aos países desenvolvidos, basicamente via o domínio de técnicas e absorção de tecnologias maduras que resultam em inovações "para o país", "para um ramo industrial", ou mesmo "para uma empresa".

Em geral, esses processos envolvem uma combinação de tecnologias já conhecidas, disponíveis, e procedimentos de assimilação e adaptação de novas técnicas, em processos extensivamente estudados pela literatura. Para combinar, adaptar e absorver tecnologias, as economias emergentes desenvolvem estratégias de aprendizagem que se baseiam na imitação, na cópia e na adaptação. Ou seja, para inovarem, as empresas, os centros de pesquisa e mesmo as universidades dos países em desenvolvimento servem-se do conhecimento já disponível para: (i) elevar a qualificação da economia e, principalmente, das empresas; e (ii) otimizar o desenvolvimento de atividades inovadoras em ambientes de escassez de recursos (Hobday, 1994; Kim, 1997; Mathews, 2001; Sheehan, 2008; Caraça et al., 2009). Amsden (1989, 2001) e Kim (1997) mostraram como a adoção de estratégias de catching up está na raiz da evolução de um grupo de países asiáticos - em especial a Coreia do Sul e Taiwan - que conseguiram capacitar suas empresas e transformá-las em players globais num curto espaço de tempo. Esses autores enfatizaram também a insubstituível atuação do setor público nesse processo, seja via políticas de incentivo, seja por meio da reconfiguração ou criação de instituições voltadas para absorção e desenvolvimento de tecnologias e inovação. Foi nessas condições que Taiwan, por exemplo, conseguiu migrar da imitação para a inovação a partir do uso sofisticado de instituiçôes como Centros Públicos de Pesquisa e Parques Tecnológicos, que potencializaram os investimentos empresariais em Pesquisa e Desenvolvimento $(\mathrm{P} \& \mathrm{D})$. O governo taiwanês desenvolveu também novos sistemas de adaptação, adoção e difusão de tecnologias, difundiu consórcios de $\mathrm{P} \& \mathrm{D}$, estimulou o depósito de patentes nos Estados Unidos (no USPTO - United States Patent and Trademark Office) e adotou estratégias de apoio à sua utilização na competição internacional nos segmentos de alta tecnologia (Mathews e $\mathrm{Hu}, 2007$, p. 2-3).

Estudos mais recentes mostram como nesses países asiáticos o sistema universitário ocupou posição de destaque precisamente por mostrar-se capaz de gerar e incentivar inovações que desencadearam fortes processos de qualificação e elevação do grau de competitividade das empresas e de suas respectivas economias (Caraça et al., 2009).

Para Mathews e Hu (2007), a participação das universidades no desenvolvimento desses países não constrangeu a dinâmica da pesquisa, não inibiu a criatividade e a liberdade dos pesquisadores, tampouco afetou negativamente a necessária autonomia que as instituições de pesquisa precisam ter para gerar conhecimento novo. Pelo contrário, segundo seus estudos, ao entrarem em sintonia com o esforço de superação desses países, e diminuírem seu insulamento, a universidade aumentou sua contribuição para a sociedade e também para o próprio conhecimento. Em outras palavras, foi graças ao reordenamento de suas práticas e objetivos que a universidade pôde se sobressair no arco das instituições voltadas para a inovação e contribuir para o rápido desenvolvimento dos países asiáticos. Por conta dos avanços significativos alcançados, esses países concorrem atualmente de igual para igual com as economias mais avançadas em vários domínios da economia, da ciência e da tecnologia.

Desde o início dos anos de 1990, outros países enveredaram por trilhas semelhantes, buscando o 
catch up e ensaiando avanços ainda maiores. Embora com estilos e estruturas distintas, a China (Kim e Mah, 2009; Hu e Mathews, 2008), a Índia (Vaidyanathan, 2007; Athreye e Godley, 2009; Alfaro e Chari, 2009) e, mais recentemente, também o Brasil (Arbix e De Negri, 2009; Arbix e Martin, 2009; Armijo e Burges, 2010; Sheehan, 2008), para citar algumas das grandes economias, revalorizaram as políticas industriais e de inovação, criaram novas instituições e passaram a se utilizar mais intensamente de um conjunto de políticas públicas, elaboradas e executadas a partir de uma presença mais vigorosa do Estado na economia e na sociedade.

$\mathrm{Na}$ China e na Índia as universidades ocuparam - e ocupam cada vez mais - um lugar especial para a realização de suas estratégias de desenvolvimento. Consideradas a principal fonte de produção de conhecimento novo, as universidades receberam os mais variados incentivos para construir sistemas de reconhecimento de inovações, patenteamento, licenciamento, difusão e transferência de conhecimento e tecnologia.

A visão difundida por Etzkowitz (2003), de que a universidade é tanto fonte de conhecimento como espaço propício à inovação, e de que essas inovaçôes são passíveis de serem transferidas para a sociedade, encontra suporte em várias experiências chinesas e indianas atuais. Nesses países, as universidades modificaram sua estrutura legal, organizacional e de governança, com profundo impacto em suas atividades de pesquisa e em suas relações com a sociedade (Kim e Mah, 2009; Sheehan, 2008). Essas mudanças adaptaram, reformaram ou criaram instituições multidisciplinares de ensino e pesquisa, sofisticaram os mecanismos de geração e incubação de empresas de base tecnológica, assim como estimularam a implantação de sistemas de proteção do conhecimento produzido e desenvolvido pela comunidade de pesquisadores, seus núcleos, centros e laboratórios.

No Brasil, apenas mais recentemente e ainda em menor intensidade, motivaçôes semelhantes também estimularam mudanças no sistema universitário para além das preocupações com sua expansão e melhoria de qualidade do ensino. Nesse sentido, a aprovação da Lei de Inovação (Lei no 10.973/2004) pelo Congresso em 2004 marcou uma inflexão na trajetória do sistema de gestão da propriedade intelectual e de transferência de tecnologia na universidade brasileira, ao dar amparo legal e definir incentivos para a comercialização dos resultados das pesquisas científicas e tecnológicas.

A Lei de Inovação estabeleceu um conjunto de instrumentos e facilitou a cooperação entre a pesquisa acadêmica e as empresas. Nesse novo marco encontra-se a obrigatoriedade de criação de Núcleos de Inovação Tecnológica (NITs) nas Instituições de Ciência e Tecnologia (ICTs). ${ }^{1}$ Os NITs, concebidos para se tornarem referências no diálogo e no relacionamento com o setor empresarial, devem também se responsabilizar pela defesa e proteção da propriedade intelectual e da inovação. Dessa forma tais núcleos, pensados como facilitadores, promoveriam parcerias com agentes externos e zelariam pela disseminação de uma cultura de transferência de tecnologia, ainda pouco consolidada nas instituiçōes de Ciência e Tecnologia (C\&T) no Brasil.

Nos primeiros cinco anos após a aprovação da Lei de Inovação, dezenas de NITs foram criados no Brasil. Dados de 2009 indicam que, das 101 ICTs públicas que anualmente encaminham informaçōes ao Ministério de Ciência e Tecnologia (MCT), 75 já haviam criado um NIT. Como há benefícios para esse tipo de iniciativa, mesmo as universidades privadas ou quase-privadas (que respondem por uma parcela menor da pesquisa científica no Brasil) têm empreendido esforços para estruturarem seus NITs (Torkomian, 2009).

Várias universidades brasileiras já mantinham estruturas análogas aos NITs, antes mesmo da obrigatoriedade definida pela Lei de Inovação. Agências de inovação, escritórios de transferência de tecnologia e núcleos de propriedade intelectual são versōes diferenciadas de uma mesma preocupação. A novidade é que a Lei, ao institucionalizar e regulamentar essas atividades, estruturou um sistema de incentivo às pesquisas que se voltam para $o$ ambiente produtivo e para a economia, tendo ampliado o escopo de atuação dessas instituições.

No entanto, nossa pesquisa revelou que há ainda uma carência de entendimento dos sistemas de proteção do conhecimento, assim como dos processos de licenciamento de patentes e de tecnologia nas universidades. Não somente as figuras jurídicas 
são relativamente recentes, como são ainda escassos os estudos sobre as funções, as atribuições, a atuação e os desafios enfrentados pelos NITs, uma das preocupações do presente artigo.

Exatamente por isso, nosso estudo deteve-se no acompanhamento da trajetória de mudanças institucionais relacionadas com a construção de NITs em uma das principais universidades públicas brasileiras: a Universidade Estadual de Campinas (Unicamp). A Agência Inova - o "NIT" criado pela Unicamp antes mesmo da Lei de Inovação - foi escolhida não somente pelo seu pioneirismo, mas também por ter se tornado uma referência para outras ICTs no Brasil, dado o destaque alcançado por seus resultados, pela qualificação de seus recursos humanos e volume de recursos orçamentários. Mais ainda, a Agência Inova possui objetivos claramente delineados, assim como se apoia em regras flexíveis e mais adequadas ao diálogo com as unidades de pesquisa, características que, acreditamos, sustentam sua eficiência e dinamismo institucional. ${ }^{2}$

Numa perspectiva comparativa, este artigo também analisa a experiência de dois outros NITs: (i) a Agência de Inovação da Universidade de São Paulo (USP) e (ii) a Agência de Gestão Tecnológica da Pontifícia Universidade Católica do Rio Grande do Sul (PUC-RS). A USP é a maior universidade pública do país e responde por cerca de 30\% da produção científica brasileira; e a PUC-RS é uma universidade privada que, juntamente com a PUC-Rio de Janeiro e a PUC-São Paulo, representa a ponta mais avançada do grupo das Universidades Católicas, além de buscar excelência científica nas áreas de incubação e transferência de tecnologia.

Para procedermos à análise dessas experiências, foram realizadas visitas às três instituiçôes, acompanhadas de entrevistas qualitativas semiestruturadas com diretores e funcionários ao longo do segundo semestre de 2009, além de extensa consulta a material secundário, entre os quais se destacam os relatórios de atividades produzidos por tais instituições.

Este artigo se organiza em três seçôes e uma conclusão: a primeira realça experiências internacionais selecionadas de modo a explicitar a resistência do modelo linear de inovação e as novas alternativas que enfatizam o papel proativo que as universidades podem desempenhar. A segun- da discute o caso brasileiro, com destaque para os passos recentes efetivados pelo setor público, em particular o Federal, na direção da construção de uma nova política de desenvolvimento baseada na inovação. Na terceira seção, discute-se a efetividade dos Núcleos de Inovação Tecnológica, e à luz da experiência da Agência Inova da Unicamp destaca algumas das principais dificuldades à sua atuação plena. $\mathrm{Na}$ conclusão, damos início a uma reflexão sobre os avanços observados no sistema nacional de C\&T brasileiro, com destaque para a necessidade de seu reordenamento e reforma. Esta posição é reforçada aqui, ao argumentarmos que tais mudanças constituem uma meta necessária caso o país pretenda avançar na construção e na consolidação de uma estratégia baseada na inovação, que tem nas universidades peça essencial.

\section{$\mathrm{O}$ arco da ciência e da inovação}

Instituições tradicionais e de grande porte mudam seus objetivos e práticas lentamente. Nos países que adotaram estratégias de desenvolvimento para superarem seu atraso, as pressões por reformas no sistema de ensino e pesquisa ganharam corpo ainda nos anos de 1970, com os primeiros impactos das tecnologias de informação e comunicação. No caso dos "Tigres Asiáticos", as mudanças foram de vulto e se mostraram determinantes para a alteração do metabolismo de suas economias a partir das transformações dos processos de geração, transferência e difusão do conhecimento.

Num primeiro momento, os questionamentos voltaram-se contra o repertório de técnicas, hábitos e culturas consolidados ao longo do século XX, estabelecido com base na primazia da indústria sobre o conjunto da atividade econômica. Grades curriculares, métodos de ensino, processos de produção, transmissão e difusão de ciência, tecnologia e da inovação tornaram-se alvo de debates que estremeceram as universidades.

É importante registrar que até a explosão da revolução da informática, os professores universitários, como regra, mantinham seu foco na docência e em pesquisas individuais. Apenas ocasionalmente a integração com outros departamentos e disci- 
plinas ia além de proclamaçóes genéricas sobre a necessária confluência de saberes para um melhor entendimento dos fenômenos sociais e econômicos. Desse prisma, o insulamento da universidade era tido como um mecanismo de defesa contra o dirigismo e a captura da pesquisa por interesses particulares, advindos do mercado ou do universo da política. David Audretsch, um dos principais pesquisadores sobre as relaçóes entre universidade e sociedade, afirmou cruamente que, até os anos de 1970, as "universidades não desempenhavam um grande papel na economia". ${ }^{3}$

No século XIX, segundo Etzkowitz (2002, 2003), a universidade viveu uma verdadeira revolução acadêmica, que adicionaria à docência uma segunda missão, a da pesquisa, conhecida ao longo do século XX como Pure Basic Research. A partir dos anos de 1970, a universidade passou a ser convidada, quando não, pressionada, a ampliar o espectro de sua contribuição para o desenvolvimento econômico e social. Essa demanda abriu um capítulo tão polêmico quanto desafiador, não só para a comunidade acadêmica mas também para a sociedade como um todo. Desse processo emergiria, segundo Etzkowitz e Leydesdorff (1999), mais uma grande inflexão na trajetória histórica da universidade, consubstanciada em uma nova missão. As características dessa nova missão foram sintetizadas por Etzkowitz como sendo a da "pesquisa que contribui para o desenvolvimento da sociedade" (2002, p. 27).

$\mathrm{O}$ debate incluiu terminologia nova, como a expressão "universidade empreendedora", que teria condições efetivas de ampliar a atuação da comunidade acadêmica ao envolver-se ativa, livre e conscientemente na busca do desenvolvimento econômico e social. Em que pese a carga negativa que o termo "empreendedor" carrega para algumas vertentes das ciências humanas (Etzkowitz, 2003), a referência era importante pois expressava a ideia de recuperação das concepções de Schumpeter sobre a inovação como motor da economia, e não a uma visão dos processos educativos ligados à vulgarização ou mercantilização do ensino e da pesquisa.

Nessa chave, a trajetória evolutiva da atuação universitária foi ilustrada e classificada por Stokes (1997, pp. 72-75) basicamente por meio de dois "quadrantes" aptos a captar os diferentes níveis de ocorrência da Pesquisa Básica Pura (ao estilo de Niels Bohr) e da Pesquisa Aplicada Pura (cujo ícone seria Thomas Edison). A terminologia utilizada atendia mais à disposição de Stokes de construir uma tipologia do que à atribuição e identificação de conceitos a certas atividades acadêmicas. Stokes introduziu também em sua análise um terceiro quadrante, destinado ao que chamou de Pesquisa Básica Inspirada no Uso e cuja referência seria Louis Pasteur (Figura 1).

Figura 1

\section{Modelo do Quadrante da Pesquisa Científica}

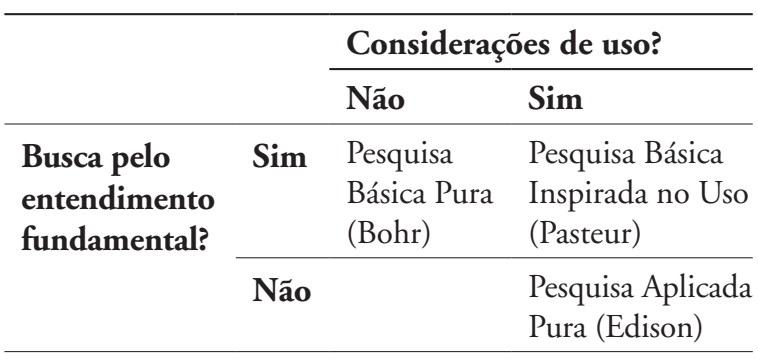

Fonte: Stokes (1997, p. 73).

Romer (2005, p. 10) reconfigurou o diagrama de Stoker sugerindo uma nova combinação - ou outro quadrante - denominado "Aplicação Inspirada na Pesquisa Básica". Sua crítica a Stokes ateve-se às limitações de seus "quadrantes", incapazes, segundo ele, de capturar os fluxos de conhecimento que ligam e alimentam incessantemente a realidade aos níveis mais abstratos da atividade científica, como numa via de mão-dupla. A proposta de Romer assumiu a forma a seguir, conforme Figura 2.

\section{Figura 2}

\section{O Arco da Ciência}

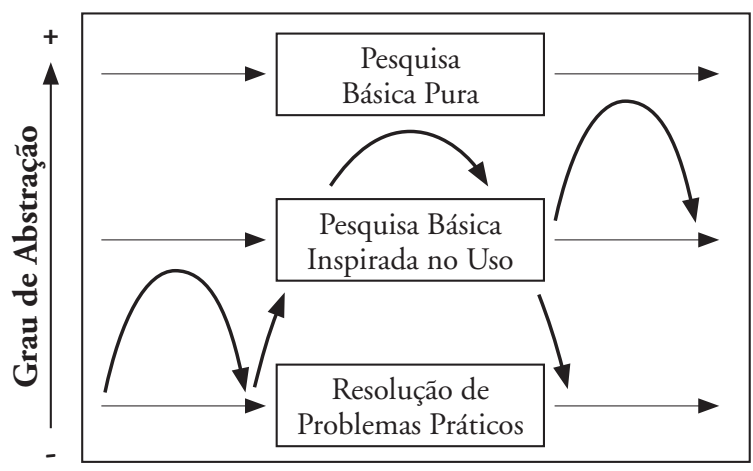

Fonte: Romer (2005, p. 11). 
Romer defendeu sua releitura com o seguinte exemplo:

Funcionários de baixa qualificação que trabalham para a Texaco na Louisiana poderiam procurar um método mais eficiente para refinar o petróleo. Por sua vez, engenheiros químicos desta mesma planta poderiam identificar abstratamente um processo de "destilação", que ligaria os problemas da refinaria da Texaco com problemas existentes em algumas destilarias de uísque. Outros engenheiros ainda poderiam formular representações matemáticas do processo de destilação e associá-las a equações fundamentais que descreveriam a relação entre calor, temperatura e pressão (Romer, 2005, p. 12).

Das três possibilidades, Romer concluiu: "Cada uma dessas etapas representa uma abstração adicional relativa a um problema prático. Porém, ao revelar sintonia com os problemas da Texaco, cada abstração é capaz de potencializar soluções para problemas enfrentados por outros, que lidam com outras disciplinas e em outros contextos" (Idem, ibidem).

As contribuiçôes de Romer certamente elevaram o nível do debate sobre as relações entre a ciência e a produção científica, com profundas implicações para as políticas públicas e para a universidade.

A partir de pesquisas realizadas na África do Sul, Cooper (2009, p. 57) denominou a produção científica que atua sobre a evolução da sociedade de Pesquisa Inspirada no Uso, semelhante à Pesquisa Básica Inspirada no Uso, sugerido por Romer (2005) a partir da releitura do diagrama de Stoker (1997).

Em que pese a disputa terminológica, no coração do debate encontram-se duas visões muito distintas, ainda que relacionadas:

1. Se o conhecimento novo é gerado a partir da pesquisa básica e evolui de acordo com sua lógica interna, a direção do progresso científico não sofre a interferência de demandas dos mercados e das sociedades. Nessas condições, o que ficou conhecido como o modelo linear de produção de inovação e tecnologia bastaria para explicar o desenvolvimento científico. ${ }^{4}$
2. Diferentemente, Romer $(1992,2005)$, na esteira de Colyvas et al. (2002), sugeriu que o direcionamento da pesquisa básica e da atividade científica está determinado pelos problemas práticos que as sociedades precisam resolver. Segundo o autor, é certo que o novo pode ser obtido por vias lineares, que seguem dos laboratórios para os mercados; suas pesquisas, porém, indicaram por que e como, frequentemente, os caminhos que levam ao conhecimento novo apontam no sentido inverso. Ou seja, muitas vezes, o conhecimento novo nasce nas empresas, desenvolve-se nos mercados e deflagra novos processos nas universidades e centros de pesquisa. Por isso, em um de seus principais alertas, Romer assinalou que o "centro da discussão era a inadequação do modelo linear como um guia para as políticas públicas" (2005, p. 12).

A visão crítica de Romer sobre a linearidade da geração do novo abriu novas perspectivas para a reflexão sobre a universidade. De fato, liberou as análises e os estudos tanto sobre a rigidez hierárquica - que fixa etapas para a geração do conhecimento -, como sobre o sentido do comportamento provinciano ou enclausurado, ao reintegrar na reflexão o conhecimento científico e tecnológico não acadêmico. Suas análises ensejaram uma série de recomendações às universidades em vias de repensar sua institucionalidade, como a ampliação significativa da interdisciplinaridade, tendo como base a multiplicação dos vasos comunicantes entre disciplinas, unidades e estruturas organizativas; ou a abertura de canais externos voltados para o diálogo sistemático com a sociedade e o contato com a economia. Suas propostas, longe de secundarizar os processos abstratos que movem a ciência, foram no sentido de intensificar os fluxos de conhecimento e permitir que a pesquisa seguisse seu curso e fizesse suas escolhas, mas que estivesse permeável aos insumos advindos do plano da experiência real.

$\mathrm{Na}$ década de 1980, várias universidades norte-americanas, públicas e privadas, como Stanford, Berkeley e o Massachusetts Institute of Technology (MIT), retomaram uma reflexão sobre a teoria e a prática das universidades, tendo como pano de fundo as mudanças na estrutura econômica susci- 
tadas pela emergência e rápida disseminação das tecnologias de informação e comunicação que começavam a virar a página do mundo industrial. A reestruturação da economia já se mostrava mais dependente do conhecimento do que os sistemas de produção que predominaram no século passado. A acelerada expansão de formas novas de produção e reprodução da vida material alteraria rapidamente o tecido econômico e social dos países desenvolvidos e em desenvolvimento, com fortes raízes no universo industrial.

As mudanças na demanda de profissionais pelo mercado de trabalho incidiriam sobre a estrutura dos cursos acadêmicos de formação de profissionais, questionariam a autossuficiência de antigas disciplinas e levariam as universidades a prestar mais atenção a alguns territórios que se mostravam mais propícios ao surgimento de inovações e tecnologias.

Com o surgimento do Vale do Silício, na Califórnia, berço das modernas tecnologias da informação e comunicação, muitas universidades foram levadas a contratar profissionais externos, como professores, pois a explosão de conhecimento vinha das empresas e sua continuidade pedia o entrelaçamento entre a indústria nascente e a universidade. A ideia de Romer, de Pesquisa Básica Inspirada no Uso encontrava suporte na realidade. A tradicional distinção entre ciência básica e aplicada mostrou todos os seus limites e apontou as vantagens do estreitamento das relações entre os centros produtores de ciência e as empresas para toda a sociedade.

Áreas de fronteira como a biotecnologia e a nanotecnologia, novos materiais, biologia molecular, bioquímica e neurociência, entre outras, permitiam agora uma aproximação inédita entre empresas, universidades e centros de pesquisa, dando substrato ao que Pisano (2006) chamou de "negócios baseados na ciência", ou seja, empresas cujos negócios são totalmente dependentes da pesquisa básica, e vice-versa. As visões predominantes no pós-Guerra, que consideravam as empresas como entidades apropriadoras do conhecimento gerado nos e pelos centros acadêmicos (exatamente porque dissociados dos mercados), perderam sustentação.

A distância entre pesquisa e empreendimento tornou-se menor. A partir disso, marcos regulatórios foram alterados, novos instrumentos foram criados e uma nova organização do mundo da produção e dos serviços começou a se configurar.

Os processos de inovação passaram a valorizar a diversidade e a atividade coletiva, assim como as redes (locais, regionais, nacionais e internacionais), que tornaram ingênuas as aproximações com as imagens heroicas do cientista inventor. Impulsos externos levaram muitas universidades de ponta a construírem incubadoras e parques tecnológicos, como meio de estimular a formação de empresas startups, como forma de diversificar suas ferramentas, readequar suas normas e de aplicar seus conceitos numa cooperação mais estreita com a economia real.

As novas dinâmicas de geração de conhecimento também ajudaram a consolidar a percepção de que temas como as desigualdades entre países, pobreza, mudanças climáticas e envelhecimento das sociedades, para citar alguns, não seriam tratados satisfatoriamente se obedecessem às fronteiras tradicionais das disciplinas ou se fossem ancorados nos limites estritos da racionalidade que rege a produção acadêmica.

Nos países avançados, ao longo dos anos de 1990, áreas científicas como engenharia, medicina, biologia, física, química - assim como as de negócios e de economia -, começaram a se expandir e mesmo a romper a redoma de vidro que ainda envolvia a universidade. Novos programas, centros multidisplinares e novos currículos foram criados para estimular a intersecção de saberes, experiências, histórias, abordagens e culturas, assim como para aumentar os canais de comunicação com a sociedade.

$\mathrm{Na}$ maior parte dos países em desenvolvimento, que ainda buscam a industrialização, a emergência de novas tecnologias modificou os termos do debate sobre a natureza dos constrangimentos estruturais que dificultam a evolução de suas sociedades. Abriram-se novas possibilidades de superação de sua condição, sem que necessariamente tivessem de passar pelas mesmas fases e experiências dos países avançados.

\section{C\&T\&I no centro da agenda}

Por décadas, o desenvolvimento tecnológico e a inovação foram vistos mais como um subproduto 
do crescimento econômico do que como um pré-requisito para o desenvolvimento.

Especificamente durante o período desenvolvimentista brasileiro ( $1940-1980)$, esses temas foram tratados, de forma geral, como um resultado natural do processo de industrialização. Políticas protecionistas e investimentos do Estado, combinados com o investimento estrangeiro, compuseram a fórmula utilizada para impulsionar o empreendedorismo nacional e promover a industrialização e a modernização no país. Essa combinação teve um papel central no apoio à Política de Substituição das Importaçōes (ISI) ou "industrialização direcionada pelo Estado" (Ocampo, 2004, p. 3), que se disseminou por toda a América Latina. De acordo com Prebisch (1973) e com a Comissão para o Desenvolvimento Econômico da América Latina e Caribe (Cepal), a ISI buscava: (i) absorver competências; (ii) obter acesso à tecnologia estrangeira, e eventualmente alcançar o progresso; (iii) promover a industrialização como uma precondição ao desenvolvimento; e (iv) promover o desenvolvimento, com redução da pobreza e da desigualdade, de forma automática.

A mudança tecnológica, por sua vez, era vista como um resultado linear dessa política de industrialização orientada pelo Estado, tanto de forma direta, a partir da absorção de técnicas e competências obtidas pelo contato com a tecnologia estrangeira, como indiretamente a partir dos efeitos esperados de spillovers advindos de uma industrialização extensiva e intensiva.

Particularmente no caso brasileiro, o modelo de desenvolvimento esteve associado à forte participação de empresas multinacionais de capital estrangeiro previstas para intermediar a transferência de tecnologia - do exterior para o país. De forma a viabilizar o processo de absorção de tecnologias e de spillovers, o poder público empenhou-se na estruturação de um sistema acadêmico nacional dedicado à formação de recursos humanos qualificados que pudessem ser incorporados pelas empresas nascentes como um apoio à pesquisa $e$ ao desenvolvimento tecnológico. Acreditava-se que a nascente indústria privada fosse se beneficiar das empresas estrangeiras e do conhecimento gerado pelas universidades, e com o tempo teria condições de promover sua própria $\mathrm{P} \& \mathrm{D}$ de forma dinâmica e sustentável.

No entanto, a reduzida transferência de conhecimento das universidades para as empresas foi uma das razōes que levou à criação, na década de 1950, de duas novas instituições, o CNPq e a Capes. ${ }^{5}$ Essas duas instituiçóes, ainda que tenham representado um ponto de inflexão na história da ciência e da tecnologia no Brasil, foram estruturadas a partir de ideias que corroboravam o modelo linear como um padrão que orienta a geração de inovação. Como abordado na seção anterior, o modelo linear pressupõe que o conhecimento siga um padrão em que a pesquisa básica, originada nas universidades, é convertida em inovação pelas empresas.

Em países como o Brasil, que contavam com uma indústria incipiente e com baixos níveis de investimento, empreendedorismo e inovação, essa versão "tropicalizada" do modelo linear contribuiu com o insulamento da universidade, aumentando ainda mais o distanciamento em relação às empresas (Vermulm e De Paula, 2006). Ao contrário das expectativas do modelo linear, a nascente indústria brasileira beneficiou-se apenas marginalmente do conhecimento gerado nas universidades e nos centros de pesquisa, não sendo capaz de absorver ou produzir tecnologia suficiente para criar um sistema endógeno e sustentado pelo aprendizado tecnológico e pelas inovações.

Apesar das diversas orientações que a economia brasileira recebeu ao longo do tempo, as sucessivas políticas de $\mathrm{C} \& \mathrm{~T}$ quase sempre tiveram seu foco no apoio e fortalecimento da pesquisa básica realizada pela academia. Raramente as empresas foram identificadas como alvo das políticas e dos programas de $\mathrm{C} \& \mathrm{~T}$, pois o setor produtivo continuava a ser visto como receptor de conhecimentos e de recursos humanos advindos da universidade.

Foi somente na virada do século que a promoção da inovação foi incorporada nos planos de desenvolvimento nacional como um objetivo explícito a ser perseguido. $\mathrm{O}$ primeiro passo deu-se com a criação dos Fundos Setoriais, ${ }^{6}$ em 1999. Desde então, e particularmente a partir de 2004, com a nova Política Industrial, Tecnológica e de Comércio Exterior (PITCE, 2004), e de outras medidas que se somaram, tais como a Lei de Inovação (10.973/2004) 
e a Lei do Bem (11.196/2005), visualiza-se uma linha de continuidade nas políticas do governo federal no que se refere à adoção de uma postura mais proativa em relação à inovação tecnológica.

Como ilustração, o Quadro 1 organiza informações referentes à recente trajetória da C\&T\&I (Ciência, Tecnologia e Inovação) brasileira, com destaque para as diretrizes legais, instrumentos e programas implementados nesses últimos anos, aqui organizados em dois períodos: décadas de 1990 e período entre 2003 e 2009.

Muitos dos avanços tecnológicos só foram possíveis a partir da combinação de vários elementos que se acumularam no tempo, ampliando e diversificando o sistema nacional de inovação. Avanços ocorreram em várias dimensōes e têm sido inclusive reconhecidos por instituições internacionais.

Segundo o relatório de Indicadores de Ciência e Engenharia, de 2010, tanto a Índia como o Brasil receberam destaque por conta de seus investimentos em P\&D. Dados da Unesco mostram que a Índia respondeu por cerca de US\$ 15 bilhões em P\&D em 2004; o Brasil respondeu por US $\$ 13$ bilhôes em 2005, valores que representam praticamente o dobro do que foi investido na década de 1990, e que insere esses países entre os quinze maiores investidores em $\mathrm{P} \& \mathrm{D}$ do mundo (NSB, 2010).

De acordo com o mesmo relatório, o Brasil também ganhou destaque como produtor de arti-

\section{Quadro 1}

Diretrizes Legais, Novos Instrumentos e Programas de C\&T\&I (1994-2009)

\begin{tabular}{|c|c|c|}
\hline & Década de 1990 & 2003-2009 \\
\hline Política de Inovação & $\begin{array}{l}\text { Primeiros passos: criação dos Fundos } \\
\text { Setoriais (1999) }\end{array}$ & $\begin{array}{l}\text { PITCE }-2004^{a} \\
\text { PDP }-2008^{b} \\
\text { PAC-C } \& T-2008^{c}\end{array}$ \\
\hline $\begin{array}{l}\text { Criação de uma nova } \\
\text { estrutura legal }\end{array}$ & $\begin{array}{l}\text { Lei de Proteção da Concorrência (1994) } \\
\text { Lei de Informática(1991) } \\
\text { Dedução em dobro no IR e CSLL dos } \\
\text { gastos em P\&D } \\
\text { Lei de Propriedade Industrial }\end{array}$ & $\begin{array}{l}\text { Lei de Inovação (2004) } \\
\text { Lei do Bem }(2005)^{\mathrm{d}} \\
\text { Lei de Biossegurança (2005) }\end{array}$ \\
\hline Novas Instituiçóes & $\begin{array}{l}\text { Agências Reguladoras } \\
\text { Início de operação dos Fundos Setoriais } \\
\text { CGEE }^{g}\end{array}$ & $\begin{array}{l}\text { ABDI }(2004)^{\mathrm{e}} \\
\text { CNDI }(2004)^{\mathrm{f}} \\
\text { INCTs }(123 \text { no país })\end{array}$ \\
\hline BNDES e Finep & $\begin{array}{l}\text { Coordenação das Privatizações } \\
\text { Projeto Inovar (capital de risco) }\end{array}$ & $\begin{array}{l}\text { Iniciativa Tecnológica } \\
\text { Empreendedorismo Empresarial } \\
\text { Criatec } \\
\text { Pró-Inovação } \\
\text { Subvenção Econômica } \\
\text { Programa de Venture Capital }\end{array}$ \\
\hline $\begin{array}{l}\text { Novos instrumentos } \\
\text { setoriais }\end{array}$ & $\begin{array}{l}\text { Regime automotivo (1995) } \\
\text { Lei da Informática }\end{array}$ & $\begin{array}{l}\text { Prominp (Petrobrás) } \\
\text { ProSoft expandido } \\
\text { ProFarma } \\
\text { Sibratec }\end{array}$ \\
\hline
\end{tabular}

${ }^{a}$ Política Industrial, Tecnológica e de Comércio Exterior (PITCE, 2004); ${ }^{\mathrm{b}}$ Política de Desenvolvimento Produtivo; ${ }^{\mathrm{c}}$

Plano de Ciência e Tecnologia; ${ }^{\mathrm{d}}$ Incentivos fiscais para empresas exportadoras (Lei do Bem, 2005); ${ }^{\mathrm{e}}$ Agência Brasileira de Desenvolvimento Industrial (ABDI, 2004); ${ }^{\mathrm{f}}$ Conselho Nacional de Desenvolvimento Industrial (CNDI, 2004); ${ }^{\mathrm{g}}$ Centro de Gestão e Estudos Estratégicos; ${ }^{\text {h }}$ Funtec, Institutos Nacionais de Ciência e Tecnologia (INCT).

Fonte: Autores, com base em MDIC, BNDES, FINEP e MCT. 
gos científicos: da $23^{a}$ posição no ranking em 1995 , o Brasil saltou para a 16a em 2007 (Idem). O relatório também observou que o Brasil é o país mais bem posicionado na América Latina, com uma taxa de crescimento anual de produção de artigos científicos de 10,9\%, seguido pelo México (6,7\%), Chile $(5,8 \%)$ e Argentina (4,6\%).

O desafio agora é sintonizar esses avanços com o setor produtivo. Os ganhos, em termos de competitividade e de melhoria do padrão das relações de trabalho advindos de empresas que investem em tecnologias e que inovam de forma contínua, são significativos. Estudos elaborados pelo Ipea revelaram que mais de 30\% das empresas industriais brasileiras promovem inovação tecnológica de produto e/ou processo a cada dois anos. Essas empresas remuneram melhor seus empregados (em média em $80,5 \%$ a mais se comparado com o restante da indústria), demandam trabalhadores mais escolarizados (em média $20,9 \%$ a mais) e revelam maior estabilidade no emprego (cerca de $30,4 \%$ superior à média) (De Negri, 2009).

Esses mesmos estudos (De Negri, 2007) mostram que o aumento da competitividade da economia brasileira é diretamente dependente das vantagens comparativas que foram conquistadas a partir das capacidades tecnológicas das empresas e pela eficácia dos sistemas de inovação, regional e nacional. Investimentos em novos conhecimentos, particularmente os esforços em $\mathrm{P} \& \mathrm{D}$, são fortemente pró-cíclicos e tendem a aumentar de acordo com o desempenho econômico. O crescimento da economia brasileira nos últimos anos incentivou as empresas líderes a aumentarem significativamente seus investimentos em P\&D. Tanto a Lei de Inovação como a Lei do Bem criaram instrumentos de apoio às empresas em várias dimensões: (i) multiplicação dos mecanismos de incentivos fiscais à $\mathrm{P} \& \mathrm{D}$ com aplicação automática; (ii) programas de subsídios para projetos de desenvolvimento tecnológico; (iii) mecanismos de subsídios para fixação de pesquisadores em empresas; e (iv) programas de financiamento para a inovação com capital de risco.

Quanto à cooperação entre os setores público e privado, a Lei de Inovação trouxe avanços importantes, pois foi pensada para criar novos modelos de sinergia, de forma que as empresas pudessem se uti- lizar do conhecimento gerado pelas ICTs brasileiras. É neste contexto que se insere a criação dos NITs, objeto de análise nesse artigo e foco de discussão da próxima seção, que também se dedica a investigar a trajetória da institucionalização dos NITs em algumas das principais universidades brasileiras.

\section{Mudanças nas universidades brasileiras}

Nos países avançados, as universidades têm investido intensivamente nas atividades de patenteamento e licenciamento de tecnologia desde a década de 1970. O número de patentes praticamente duplicou a cada cinco anos entre 1979 e 1999. Em 1980, nos Estados Unidos, apenas vinte universidades possuíam escritórios de transferência de tecnologia. Em 1990 passaram a ser duzentas. No ano 2000, todas as universidades norte-americanas com atividades de pesquisa possuíam seu escritório de licenciamento e de transferência de tecnologia (Colyvas et al., 2002, p. 1).

Muitos analistas vinculam esse crescimento à promulgação do Bayh-Dole Act, aprovado pelo Congresso norte-americano em 1980. O Bayh-Dole Act teve seus efeitos ampliados por meio do Patent and Trademark Clarification Act de 1984 e permitiu que universidades, pequenas empresas e organizações sem fins lucrativos se tornassem proprietárias de tecnologias desenvolvidas com financiamento público. Esse incentivo à defesa da propriedade intelectual levou as universidades norte-americanas a acelerar a implantação de escritórios de transferência de tecnologia e a estreitar seu relacionamento com as empresas privadas.

Nesse sentido, as características empreendedoras da universidade norte-americana ajudam a explicar esse desempenho. Trata-se de instituições cuja organização interna abriga uma série de grupos de pesquisa "que revelam qualidades semelhantes às empresas, especialmente no que se refere ao financiamento da pesquisa, obtido a partir de um padrão competitivo" (Etzkowitz, 2003, p. 74).

O Bayh-Dole Act foi uma das fontes de inspiração para a Lei de Inovação brasileira, lei esta que, ao institucionalizar a comercialização dos resultados das pesquisas acadêmicas, estimula o relacionamen- 
to entre as universidades e a iniciativa privada. Para isso, a Lei requer que todas as ICTs públicas criem uma unidade própria, isto é, um NIT, responsável por gerir as políticas de inovação nessas instituições.

Tal gerenciamento implica diversas funções. Os NITs, de forma geral, são os responsáveis por intermediar o relacionamento entre ICTs, setor privado e governos, em suas várias dimensões. Basicamente, respondem pelos registros de propriedade intelectual; viabilizam e conduzem os processos de licenciamentos de tecnologia; articulam projetos colaborativos de pesquisa com outras organizações, especificamente nos casos em que o sigilo das informaçôes for requisitado; e incentivam a atividade de empreendedorismo no ambiente acadêmico, como facilitadores da criação de empresas de alta tecnologia. Entretanto, em parte devido ao curto período de funcionamento dos NITs no Brasil, em parte devido a determinações internas da instituição a que respondem, são poucos os exemplos de NITs que desempenham todas as atividades descritas e prescritas na Lei de Inovação. $\mathrm{O}$ mais comum é encontrar NITs envolvidos com a condução dos processos de patenteamento e licenciamento, assim como de intermediação de projetos com empresas públicas ou privadas.

As três agências aqui apresentadas são exemplos de NITs vinculados a importantes universidades brasileiras que procuram consolidar sua atuação em todas essas frentes, embora difiram entre si quanto a engajamento, estrutura organizacional e indicadores de resultados.

A PUC-RS, por exemplo, adota uma estrutura descentralizada, com unidades independentes quanto às suas funçôes e atribuiçôes, ainda que preservando grande sintonia em termos da atuação. A Agência de Gestão Tecnológica (AGT), criada em 1999 , tem como missão ser uma entidade de fomento e uma facilitadora dos processos de interação universidade-empresa, viabilizando e estimulando a criação de projetos conveniados com entidades públicas e privadas. As ações da AGT são complementadas por outras três instituições vinculadas à PUC-RS, e que integram a Rede Inova PUC - Rede de Inovação e Empreendedorismo da PUC-RS: o parque científico e tecnológico (Tecnopuc), criado em 2002 com a missão de estreitar as relações de pes- quisa e inovação com as empresas; a Incubadora de Empresas de Base Tecnológica (Raiar), criada em 2003; e o Escritório de Transferência de Tecnologia (ETT), criado em 2005, unidade que apoia a AGT nas questôes referentes à propriedade intelectual dos resultados da pesquisa cooperada, bem como nas iniciativas de transferência de tecnologia.

Em oposição, as Agências da USP e da Unicamp adotaram uma estrutura organizacional mais centralizada, com a presença de uma diretoria central responsável por conduzir todos os assuntos referentes às atribuições de um NIT. Sobre este último aspecto, a Agência de Inovação da USP, criada em 2005, ainda que se envolva em projetos de estímulo ao empreendedorismo na comunidade acadêmica (por exemplo, ao organizar a competição bi-anual das Olimpíadas USP de Inovação), tem um envolvimento mais limitado com a incubadora de empresas da USP, o Cietec (Centro de Inovação, Empreendedorismo e Tecnologia). Isso porque o Cietec, criado em 1998, revela estrutura própria e encontra-se bastante consolidado.

Por sua vez, a Agência Inova, criada em 2003, é a gestora da incubadora de base tecnológica da Unicamp, além de ser responsável pelos registros e licenciamentos de patentes na universidade e de cuidar da gestão de projetos com empresas quando é requisitado o sigilo de informaçôes.

A trajetória vivenciada pela Inova tem-se destacado como referência no Brasil na implantação das agências de inovação, no que se refere ao modelo de gestão adotado e nos resultados apresentados. Uma das razôes para o bom desempenho dessa agência diz respeito ao engajamento das instâncias superiores da universidade, em especial da reitoria e da procuradoria geral, que implementaram tal projeto antes mesmo da promulgação da Lei de Inovação e, portanto, independentemente de qualquer obrigação legal nesse sentido.Como resultado, a agência recebeu por duas vezes (em 2006 e 2008) a premiação conferida pela Finep (Financiadora de Estudos e Projetos), "Prêmio Finep de Inovação Tecnológica", Região Sudeste, na categoria "Instituição de Ciência e Tecnologia” e, em ambas as situações, recebeu menção honrosa pelo segundo lugar na premiação Nacional. ${ }^{7}$

Ademais, em 2007 foi assinado um contrato com a Finep para que a Inova repassasse sua experiên- 
cia para os NITs em formação no Brasil. Trata-se do projeto Inovanit, voltado à capacitação dos gestores dos NITs, que visa a auxiliá-los no processo de implantação de seus núcleos de inovaçãao tecnológica. ${ }^{8}$

A discussão que se segue busca analisar a experiência da Inova com a proteção e a transferência das tecnologias geradas na universidade, com atenção para seus principais resultados e realizações. Três perspectivas são contempladas: (1) proteção e comercialização da propriedade intelectual; (2) promoção de uma cultura inovadora na universidade; e (3) resolução dos principais problemas que impedem ou dificultam a plena efetividade e continuidade das açôes da Inova. Os casos da Agência de Inovação da USP e da AGT serão trazidos para o debate apenas com a finalidade de obtermos uma compreensão geral sobre o processo de institucionalização dos NITs nas universidades brasileiras.

\section{Os NITs e a propriedade intelectual}

Esta seção discute a efetividade das açōes exercidas pelos NITs na condução do processo de patenteamento e de licenciamento de tecnologias. No que diz respeito à proteção da propriedade intelectual, o ponto a realçar é que a preocupação com as patentes nas universidades brasileiras começa bem antes da edição da Lei de Inovação. Pesquisadores, sobretudo das instituições públicas (USP e Uni- camp), têm conduzido pesquisas que objetivam o patenteamento de suas tecnologias há décadas. No entanto, o processo de transformar invenções em inovaçōes a partir do licenciamento e do uso comercial desse conhecimento pouco tem avançado. Isso significa que o licenciamento de patentes requer um know-how poucas vezes encontrado junto aos pesquisadores das universidades, que nem sempre sabem ou se dispōem a conduzir esse processo.

Após o decreto da Lei de Inovação, no entanto, com a institucionalização de um espaço específico para cuidar desses assuntos - nesse caso, os NITs -, todas as atividades referentes à proteção da propriedade intelectual e à transferência de know-how nas universidades pesquisadas foram aceleradas.

A Tabela 1 traz números que acentuam os esforços empreendidos pelas três agências no estabelecimento de pontes entre a pesquisa interna e o mercado. Ainda que o caso da Inova se sobressaia em todos os itens de comparação (registros de patentes no período anterior e posterior à criação dos NITs, licenciamentos e valores relativos a royalties que retornaram para a universidade), é oportuno mencionar o salto que a USP e a PUC-RS deram no número de patentes registradas em um curto período de tempo, exatamente após a institucionalização dos NITs, se comparado com o período que antecede a essa estrutura. Os números de licenciamento dessas tecnologias também são dignos de nota, sobretudo no caso

Tabela 1

Números de Patentes, Licenciamentos e Royalties em Agências de Inovação Selecionadas

\begin{tabular}{llll}
\hline & $\begin{array}{l}\text { Agência Inova } \\
\text { Unicamp }\end{array}$ & $\begin{array}{l}\text { Agência Inovaçáo } \\
\text { USP }\end{array}$ & $\begin{array}{l}\text { AGT/ETT* } \\
\text { PUC/RS }\end{array}$ \\
\hline $\begin{array}{l}\text { Pedidos de patentes no INPI - antes da } \\
\text { criação da Agência }\end{array}$ & $\begin{array}{l}(1989-2003) \\
258\end{array}$ & $\begin{array}{l}(1982-2004) \\
246\end{array}$ & 0 \\
\hline $\begin{array}{l}\text { Pedidos de patentes no INPI - depois da } \\
\text { criaçáo da Agência }\end{array}$ & $(2004-2009)$ & $(2005-2009)$ & $(2000-2009)$ \\
\hline Número de Licenciamentos & 298 & 264 & 51 \\
\hline Valor dos Royalties & $(2004-2008)$ & $($ até 2008) & $($ até 2009) \\
& 38 & 16 & 7 \\
\hline
\end{tabular}

* AGT - Agência de Gestão Tecnológica; ETT - Escritório de Transferência de Tecnologia.

Fonte: Entrevistas com as agências e relatórios de atividades. 
da PUC-RS, o que revela um esforço no sentido de transformar as patentes em inovaçōes no mercado.

Embora os números da Tabela 1 sejam dignos de reconhecimento, é válido reforçar que números de patentes e mesmo de licenciamentos não necessariamente indicam a presença de inovaçōes prontas para o mercado e com potencial de viabilizar retornos econômicos aos seus criadores. O depósito da patente é apenas a primeira da etapa da proteção do conhecimento; para se tornar uma exploração comercial, deve ainda incluir o contrato de licenciamento, compreendendo um período de desenvolvimento na e pela empresa até que essa patente se torne um produto ou processo com potencial para aplicação comercial e industrial. Se após esse período a ideia chega ao mercado na forma de uma inovaçãa, a remessa de royalties para a universidade passa a ser garantida.

Mais uma vez, a Lei de Inovação trouxe avanços importantes sobre esse assunto, com diretrizes que orientam a forma como os royalties devem ser distribuídos na universidade. Como as negociações relativas aos licenciamentos não são padronizadas, o percentual que é devido à universidade varia em cada caso, com contratos discutidos entre a empresa e a Universidade/NIT. A padronização apenas ocorre em relação ao montante de recursos que é repassado à universidade: $1 / 3$ fica com o(s) detentor(es) da patente, $1 / 3$ é direcionado à unidade (faculdade ou instituto) do(s) patenteador(es) e 1/3 para a reitoria. A reitoria, nesse caso, decide se ficará com o recurso ou se fará um repasse para o NIT, como por exemplo ocorre com as agências da Unicamp e da USP.

Sobre esse aspecto, os valores relativos aos royalties recebidos pelas universidades, conforme a Tabela 1 indica, conduzem a duas leituras distintas: do ponto de vista da universidade, trata-se de valores marginais se considerarmos os investimentos em pesquisa que são realizados. Já da perspectiva do(s) pesquisador(es), representam uma gratificação pelos esforços empreendidos e um forte estímulo para que os demais pesquisadores não apenas patenteiem, mas também busquem o licenciamento de seus inventos.

É importante registrar que após a criação da Agência Inova (Unicamp) as patentes (que em média tiveram crescimento acelerado após 2002) não mais ficaram circunscritas ao mercado local. Os números de registros no exterior, via Tratado de Cooperação em Patentes (PCT, que tem desdobramentos em vários países), somaram 33 casos entre 2004 e 2008. É válido supor que o número de licenciamentos verificados depois da criação da Inova, em um total de 38 casos, em ritmo crescente como mostra a Figura 3 , demandou uma proteção do conhecimento com alcance mais amplo. Até então, apenas seis patentes haviam sido licenciadas e exploradas comercialmente em toda a história da Unicamp.

\section{Figura 3}

\section{Evolução do Número de Licenciamentos de Patentes pela Unicamp} (valores acumulados e por ano)

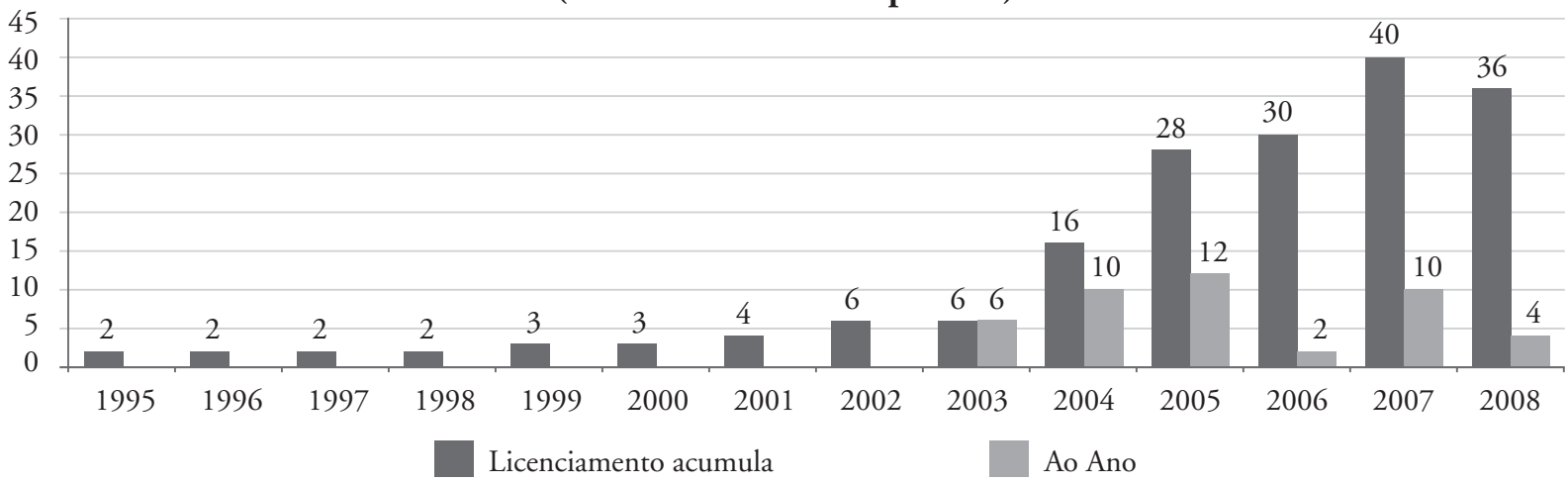

Obs.: A partir de 2006, a Lei de Inovação tornou obrigatório que todos os licenciamentos feitos com cláusulas de exclusividade sejam precedidos de edital público no Diário Oficial da União. A dificuldade em se adequar a essas novas regras explica a queda nos contratos de licenciamentos em 2006.

Fonte: Relatório de Atividades, 2008, Inova (Unicamp). 
Como se pode notar, é relevante o aumento dos pedidos de patente depositados no Instituto Nacional de Propriedade Industrial (INPI) após a criação das agências nas três universidades. No mesmo sentido, toma corpo nessas instituições a preparação e a celebração de acordos de licenciamento, em que o conhecimento gerado pelas universidades é defendido e protegido. Os números acerca dos acordos de licenciamento ainda não são muito significativos, sobretudo se olharmos para os royalties provenientes desses licenciamentos. $\mathrm{O}$ importante, porém, é registrar que os NITs introduziram esse tipo de discussão nas universidades brasileiras e estão contribuindo significativamente para disseminar uma cultura de patenteamento e de transferência de conhecimento para a sociedade.

\section{Os NITs e o estímulo à incubação}

Além de serem os responsáveis pelas atividades de proteção da propriedade intelectual e de licenciamentos de patentes e de tecnologia, os NITs também devem propor e motivar ações que aproximem a universidade com a atividade empresarial. Ao agirem assim, os NITs cumprem outra obrigatoriedade da Lei de Inovação, segundo a qual a política de inovação das instituiçôes de ciência e tecnologia deve prever o papel das incubadoras tecnológicas. ${ }^{9}$

A Tabela 2 traz informações sobre o número de empresas incubadas nessas três universidades e das empresas que já se graduaram, ou seja, empresas que, após certo período em que estiveram in- cubadas nessas instituições, adquiriram maturidade suficiente para atuar no mercado. Os números relativos à USP são muito mais significativos do que os observados nas demais incubadoras. Nesse caso, conforme já discutimos, a atuação da incubadora da USP (Cietec) independe da atuação da Agência de Inovação para dar seguimento às suas atividades. $\mathrm{O}$ mesmo não ocorre com as incubadoras da Unicamp (Incamp) e da PUC-RS (Raiar), em que a atuação das respectivas Agências de Inovação contribui para viabilizar e dinamizar esse tipo de atividade, uma vez que ambas estão diretamente envolvidas com a gestão desse processo.

Ações empreendidas pela Inova, direcionadas para a indução e a prospecção do número de projetos tecnológicos com origem na Unicamp, tendem a impactar de forma mais decisiva esses resultados. Trata-se do Inova-Semente (Suporte a Empreendimentos Emergentes em Novas Tecnologias), programa que foi anunciado em novembro de 2008. A proposta é que o Inova-Semente seja um "Centro de Empreendedorismo" especializado no incentivo integrado à criação de novos empreendimentos.

Segundo Lemos (2009), o Inova-Semente engloba as fases de captação de ideias e tecnologias, identificação, seleção e aproveitamento de oportunidades de mercado, até atingir a fase de ignição de uma empresa start-up. A ideia é trabalhar com tecnologias da universidade ainda em fase embrionária. A considerar que a atividade de incubação compreende um investimento de alto risco, os dados da Incubadora de Empresas de Base Tecnológica da Unicamp (Incamp) mostram que a instituição tem

Tabela 2

Números de Empresas, Incubadas e Graduadas, em Universidades Selecionadas

\begin{tabular}{llll}
\hline & $\begin{array}{l}\text { Agência Inova/Incamp } \\
\text { (UNICAMP) }\end{array}$ & $\begin{array}{l}\text { Agência Inovação/Cietc } \\
\text { (USP) }\end{array}$ & $\begin{array}{l}\text { AGT/Raiar } \\
\text { (PUC/RS) }\end{array}$ \\
\hline Período & $(2004-2009)$ & $(1998-2007)^{*}$ & $(2000$ a 2009) \\
\hline Empresas incubadas & 33 & 127 & 17 \\
\hline Empresas graduadas & 20 & 68 & 29 \\
\hline
\end{tabular}

* A Incubadora não é subordinada à Agência USP de Inovação. Os dados são referentes à Cietec, que faz parceria com o campus da capital.

Fonte: Entrevistas com as agências (2009). 
uma posição de destaque entre as incubadoras no Brasil. Em 2008, a Incamp foi premiada como melhor incubadora do ano na região Sudeste, na $12^{\text {a }}$ edição do Prêmio Nacional de Empreendedorismo Inovador, promovido pela Anprotec (Associação Nacional de Entidades Promotoras de Empreendimentos Inovadores). ${ }^{10}$

\section{Os NITS e alguns dos desafios à sua atuação plena}

Não obstante os aspectos positivos e os avanços evidenciados na atuação dos NITs, conforme vimos, há ainda muito que avançar na gestão, no desempenho e na consolidação de uma cultura de inovação no ambiente das ICTs brasileiras, em especial das universidades. Ainda que os NITs estejam sendo bem-sucedidos ao disseminar a percepção de que o número de patentes é algo irrelevante caso não haja a exploração comercial das mesmas, trata-se de uma atuação que necessita ser constantemente aprimorada a fim de que o número de licenciamentos seja ampliado e de fato consiga lograr sucesso e auferir retornos para a sociedade. Os desafios também são grandes, particularmente no âmbito das atividades das incubadoras de empresas, que necessitam aprimorar seus mecanismos de captação de projetos tecnológicos com chances de prosperarem e alcançarem bons resultados.

Ademais, problemas na gestão dos NITs tendem a ter impactos que podem comprometer a sustentabilidade desses centros, assim como o exercício e a continuidade de suas funçôes. A Agência Inova da Unicamp é um caso exemplar a esse respeito: depara-se com problemas relacionados a questôes orçamentárias e recursos humanos (qualificação, disponibilidade e efetivação) que, se não equacionados, tendem a comprometer a efetividade de sua atuação.

Quanto ao aspecto financeiro, uma das metas perseguidas pela Inova consiste em alcançar autossuficiência e estabilidade em termos orçamentários. Na sua composição orçamentária, os recursos têm diversas origens: uma parte está atrelada aos resultados alcançados pela Agência. Isso compreende parte dos overheads dos contratos de cooperação e de licenciamento assinados com a universidade, como também da captação direta de recursos em agên- cias de fomento a pesquisa e desenvolvimento industrial. Nessa última modalidade, Finep e CNPq destacam-se no que tange ao pagamento de bolsistas e aporte de recursos, assim como o Sebrae, com investimentos destinados às atividades que se ligam à temática do empreendedorismo. A outra parte do orçamento compreende o repasse direto de recursos vindos da reitoria, que também cede funcionários para a Agência na medida em que eles são remunerados pela universidade - o próprio diretor da Inova é professor na Unicamp. Como resultado, o mapeamento das fontes orçamentárias revela que a sustentabilidade financeira da Agência depende em larga medida de recursos captados fora, em agências financiadoras e, portanto, variáveis e com prazos de execução delimitados.

O segundo fator crítico para a gestão da Inova refere-se a recursos humanos, mais especificamente à qualificação profissional, à disponibilidade de pessoal no mercado e à capacidade de retê-los na Agência por períodos significativos.

De acordo com nosso levantamento, no ano de 2009 a Inova contava com 52 colaboradores, seguindo uma trajetória que foi crescente nos últimos anos. Não obstante, o aumento no número de colaboradores foi igualmente acompanhado pelo aumento no número de estagiários e bolsistas, que chegam a responder por mais da metade do total da equipe de profissionais da Agência. Configura-se, assim, um quadro de fragilidade, devido à dependência de colaboradores bolsistas temporários, uma realidade bastante presente não somente na Inova, mas em parcela significativa dos NITs vinculados às ICTs brasileiras.

Se de um lado é tarefa complicada encontrar no mercado profissionais com a qualificação necessária para atuar nas Agências de Inovação (isto é, com conhecimentos de pesquisa científica e de mercado), de outro, é tarefa ainda mais árdua manter o quadro de profissionais competentes, já que flexibilidade e valor dos salários estão constrangidos pela ordem financeira dos NITs, que ainda precisa ser equacionada. A demanda advinda de negociações, contatos com empresas e volume de tecnologias disponíveis, na medida em que tais fatores se elevam, aumenta consideravelmente, requerendo pessoal capacitado para atendê-la. Para dar conta 
dessas atividades, e tentar dar vazão a todo o potencial de transferência tecnológica dessas ICTs, a contratação de bolsistas e estagiários tem sido uma alternativa paliativa para os NITs. Ainda que o apoio de bolsistas seja de fundamental importância para viabilizar a atuação dessas agências na ausência de autossuficiência financeira, trata-se de uma força de trabalho instável, com tempo de vínculo determinado e cuja manutenção está fortemente atrelada aos recursos obtidos junto ao CNPq e a outras agências de fomento e financiadores.

Isso significa dizer que os NITs enfrentam um cenário de alta rotatividade que, de acordo com nossas investigações, chega a alcançar $50 \%$ ao ano. Convive-se, portanto, com uma dupla dificuldade: a de treinar pessoal e a de reter a equipe na instituição.

As questôes ligadas à autonomia orçamentária, assim como correlatas aos recursos humanos, geram fragilidade institucional que compromete fortemente a profissionalização não apenas da Inova, mas dos NITs vinculados às ICTs brasileiras de forma geral. Devem, por isso mesmo, ser objeto de reformulação a fim de não comprometerem a efetividade das açôes dessas agências no que tange à aproximação (programada) entre as universidades e a sociedade brasileira.

\section{Conclusão}

Nesse artigo procuramos reunir elementos para uma reflexão sobre o sistema universitário. Ao mesmo tempo, sugerimos de que forma as ICTs brasileiras podem se tornar indutoras de um processo dinâmico de inovação na sociedade.

A Política Industrial, Tecnológica e de Comércio Exterior (PITCE, 2004), anunciada pelo governo federal em 2004, abriu caminho para trazer o tema da inovação para o centro da agenda de desenvolvimento. Sua importância, no entanto, pode ser vista por dois ângulos: primeiro, como uma iniciativa que rompe com mais de três décadas sem uma efetiva política industrial; e, segundo, no que tange às ações a serem implementadas, a PITCE traz a inovação para o centro da agenda. Suas diretrizes combinam políticas de modernização da produção e serviços com políticas direcionadas à inovação. Deste ponto de vista, é preciso construir as ferramentas para superar as restrições estruturais da economia, de forma a torná-la mais competitiva, inovadora e menos dependente das commodities. Para que tal meta seja atingida, o sistema universitário precisa ser repensado e reestruturado.

No entanto, o setor público, as empresas brasileiras e as universidades ainda se encontram envolvidos em um processo de aprendizagem que se mostra lento, incremental e de longo prazo. A educação universitária, a pesquisa básica e a produção industrial caminharam por muitas décadas sem diálogo e apenas com pontos de contato ocasionais. Cada parte seguiu seu curso praticamente de forma autônoma, com seus vícios e virtudes. Essa fragmentação, com pesadas consequências em termos de eficiência, nunca deixou de suscitar dúvidas sobre a existência real de um sistema nacional de inovação, como tradicionalmente apontado por Lundvall (1988) e Nelson (1996, 2004). As mudanças estruturais que alteraram a economia nos anos de 1990 - principalmente no que se refere à liberalização e à privatização - expuseram as empresas brasileiras à competição externa e interna. Com a competitividade à prova em uma economia muito mais aberta, as empresas ampliaram suas preocupações com inovação e tecnologia. Ainda assim, são poucas as que realmente despertaram para a necessidade da inovação permanente como instrumento de eficiência e crescimento.

Os avanços registrados em várias universidades brasileiras, aqui representados pela atuação das Agências de Inovação da Unicamp, USP e PUC-RS, atestam que uma sintonia mais fina começou a ser estabelecida entre os principais agentes do desenvolvimento. Disciplinas e cursos novos, áreas de encruzilhada, interconexões, novas formas de financiamento de startups, instrumentos mais precisos de parceria com o setor privado estão em andamento, o que é positivo. Mas os avanços alcançados ainda são incipientes. A efetividade das açôes desses Núcleos de Inovação Tecnológica tem se expressado mais na disseminação do debate sobre Inovação nas ICTs brasileiras do que no estímulo à geração de inovações na academia e na alteração da qualidade do relacionamento universidade-empresa.

A universidade brasileira é central no projeto de transformação da economia brasileira, em es- 
pecial no que diz respeito à formação de recursos humanos qualificados e à geração de novos conhecimentos científico e tecnológico. Já as empresas são estratégicas no propósito de transformar esse roll de conhecimento em inovação para o mercado. Entretanto, assim como há fortes limitações por parte das universidades, o setor empresarial brasileiro sempre mostrou limitado interesse pelas iniciativas universitárias. Pelas informaçōes da Pintec (2007), apenas $20 \%$ das empresas reconhecem que a pesquisa universitária é importante e alvo de interesse para um trabalho cooperativo. É provável que as empresas tenham dificuldades para incorporar a inovação em suas estratégias. É possível também que apenas um pequeno grupo delas seja capaz de absorver razoavelmente o conhecimento e a tecnologia gerados pela universidade. Os dados oficiais do Inpi mostram uma clara inversão: no Brasil as empresas depositam ainda menos patentes do que as universidades. ${ }^{11}$

É necessário, no entanto, que essas instituiçōes passem a ser vistas como essenciais para o desenvolvimento do país. O esforço para mudar seus hábitos e cultura é necessário, assim como uma maior abertura para a sociedade, rompendo os muros que a separa das universidades. Não se trata de incorporar a universidade na agenda do Estado ou de aceitar uma agenda corporativa. Em outras palavras, não se trata de interferir na autonomia universitária incorporando prioridades que são perseguidas, seja pelo Estado, seja pela iniciativa privada. Cada instituição - seja o Estado, as universidades ou a iniciativa privada - deve realizar seu trabalho de forma diferenciada e com autonomia. A comunidade acadêmica, no entanto, deveria repensar a sua própria agenda de pesquisa, buscando romper com as eclusas de seus departamentos, ampliando as aberturas com a sociedade. Nesse sentido, a abordagem interdisciplinar é essencial, na medida em que os inovadores, e as inovaçōes, se encontram exatamente na encruzilhada entre várias disciplinas. Esta diversificação nos modelos de formação é crucial quando se pensa em um novo alinhamento entre universidade e sociedade.

Os avanços alcançados pelo Brasil nesses últimos anos permitem uma reflexão mais madura $\mathrm{e}$ equilibrada - e mais eficiente em termos de tecnologia e inovação - entre o desempenho das empre- sas em um mercado mais bem regulamentado e a presença dos mecanismos de estímulo e apoio, sem o intervencionismo prévio. Desse ponto de vista, o Brasil é hoje um país que, cada vez mais, se diferencia na área de C\&T global. Isso significa reconhecer a importância das medidas tomadas para a construção de uma estratégia baseada na inovação, mas a efetividade dessa mudança e dessa nova postura em que a inovação é estratégica para a competitividade do país requer continuidade, intensificação e consistência das ações. Mais ainda, requer uma universidade que se perceba e se realize como inovadora.

\section{Notas}

1 Lei de Inovação, Art. 17 - "A ICT deverá dispor de Núcleo de Inovação Tecnológica, próprio ou em associação com outras ICT, com a finalidade de gerir sua política de inovação". Por definição, ICT representa uma universidade ou um instituto de pesquisa que se dedique ao desenvolvimento da pesquisa científica ou tecnológica.

2 A Inova dissemina suas experiências para gestores de outros NITs a partir de um projeto financiado pela Finep.

3 Entrevista a Newsweek, "The Campus of the Future", 9 ago., 2008.

4 Foge dos objetivos deste ensaio realizar uma análise exaustiva do modelo linear de geração de conhecimento. Para isso, ver Rosenberg (1982, 1994); Aghion, Dewatripont e Stein (2005); Romer (1992); Nonaka e Takeuchi (1995); Nelson (1996) e Mokyr (2003).

5 Conselho Nacional para o Desenvolvimento Científco e Tecnológico (CNPq, que responde ao Ministério de Ciência e Tecnologia); e Coordenação de Aperfeiçoamento de Pessoal de Nível Superior (Capes, que responde ao Ministério da Educação).

6 Os Fundos Setoriais de Ciência e Tecnologia são instrumentos de financiamento de projetos de pesquisa, desenvolvimento e inovação no país. Existem dezesseis Fundos Setoriais, sendo quatorze relativos a setores específicos e dois transversais. Destes, um é voltado à interação universidade-empresa (FVA - Fundo Verde-Amarelo), enquanto o outro é destinado a apoiar a melhoria da infra-estrutura de ICTs (Infra-estrutura) (Finep).

7 O Prêmio Finep de Inovação foi criado para reconhecer e divulgar esforços inovadores realizados por 
empresas, instituições científicas e tecnológicas e inventores brasileiros. São duas as etapas, regional e nacional, que premiam as seguintes categorias: Micro/ Pequena Empresa; Média Empresa; Instituição de Ciência e Tecnologia; Tecnologia Social; Inventor Inovador; e Gestão da Inovação.

8 Desde julho de 2007, a Inova já ministrou 34 cursos de formação para gestores dos NITs, em onze modalidades distintas, tendo atendido 220 instituiçōes. Foram um total de 1.021 participações, tendo sido treinados 676 pessoas (em média, as pessoas têm participado de mais de uma modalidade de treinamento).

9 Ações de empreendedorismo tecnológico e de ambientes de inovação, inclusive incubadoras e parques tecnológicos.

10 Os indicadores avaliados foram: inovação, sustentabilidade e gestão.

11 Considerando o ranking das patentes requeridas ao INPI, a Unicamp aparece como a segunda instituição com o maior número de depósitos de patentes no Brasil, atrás apenas da Petrobrás.

\section{BIBLIOGRAFIA}

ACEMOGLU, D.; Aghion, P. \& ZILIBOTTI, F. (2006), "Distance to frontier, selection, and economic growth". Journal of the European Economic Association, 4 (1): 37-74.

AGHION, P ; DEWATRIPONT, M. \& STEIN, J. (2008), "Academic freedom, private-sector focus, and the process of innovation". NBER Working Papers 11542, National Bureau of Economic Research, Inc.

ALFARO, L. \& CHARI, A. (2009), "India transformed? Insights from the firm level 19882005". Harvard Business School, Working Paper, 10-030, out.

AMSDEN, A. H. (1989), Asia's Next Giant: South Korea and late industrialization. Nova York, Oxford University Press. (2001), The rise of the rest: challenges to the West from late-industrializing economies. Oxford, Oxford University Press.

ARBIX, G. \& DE NEGRI, J. (2009), "Innovation and the development agenda". Economic Socio$\log y$ - The European Electronic Newsletter, 11 (2): 16-23.
ARBIX, G. \& MARTIN, S. (2009), "Beyond the developmental State, beyond neoliberalism: rethinking State capacities in the new Brazil". Trabalho apresentado no Colóquio "The Brazilian State: Paths and Prospects of Dirigisme and Liberalization". Nova York, The Bildner Center, University of New York, 9-10 nov.

ARIFFIN, N. \& FIGUEIREDO, P. (2004), "Internationalization of innovative capabilities: counter-evidence from the electronics industry in Malaysia and Brazil". Oxford Development Studies, (Carfax Publishing - Taylor \& Francis), 32 (4): 559-583.

ARMIJO, L. E. \& BURGES, S. (2010), "Brazil, the entrepreneurial and democratic BRIC". Polity, 42: 14-37.

ATHREYE, S. \& GODLEY, A. (2009), “Internationalization and technological leapfrogging in the pharmaceutical industry". Industrial and Corporate Change, 18 (2): 295-323.

BELL, M. \& ALBU, M. (1999), "Knowledge systems and technological dynamism in industrial clusters in developing countries". World Development, 27 (9): 1715-1734.

CARAÇA, J.; LUNDVALL, B. A. \& MENDONÇA, S. (2009), "The changing role of science in the innovation process: from queen to Cinderella?". Technological Forecasting \& Social Change, 76: 861-867.

COLYVAS, J.; CROW, M.; GELIJNS, A.; MAZZOLENI, R.; NELSON, R. Rosenberg \& SAMPAT, B. (2002), "How do university inventions get into practice?”. Management Science, 48 (1): 61-72.

COOPER, D. (2009), "Universities in national development: perspectives on a second academic revolution linked to a third industrial revolution", in H. Eggins (ed.), Research summaries on sharing research agendas on knowledge systems, Paris, Unesco, pp. 54-65.

DE NEGRI, J. (coord.). (2007), “Relatório de pesquisa sobre inovação tecnológica nas empresas industriais brasileiras". Brasília, Ipea. (2009), "Trade, innovation and firm growth in Brazil: technology transfer through trade". Trabalho apresentado em OECD Global Forum on Trade Innovation and Growth, 15-16 out., Paris, mimeo. 
DOS SANTOS, M. E. R.; TOLEDO, P. \& LOTUFO, R. (eds.). (2009), Transferência de tecnologia: estratégias para a estruturação e gestão de núcleos de inovação tecnologica. Campinas, SP, Komedi.

ETZKOWITZ, H. (2002), MIT and the rise of entrepreneurial science. Nova York, Routledge. (2003), "Research groups as 'quasi-firms': the invention of the entrepreneurial university. Research Policy, 32: 109-121.

ETZKOWITZ, H. \& LEYDESDORFF, L. (1999), "Whose triple helix?". Science and Public Policy, 26 (2): 138-139.

FERRARI, A. (2001), José Pelúcio Ferreira e a pós-graduação no Brasil. Brasília, Capes.

FERREIRA, C. G. \& AUDY, J. L. N. (2008), "Gestão da inovação e empreendedorismo na universidade: o caso InovaPUC”. Locus Científico, 2 (1): 20-28.

FREEMAN, C. (2008), Systems of innovation: selected essays in evolutionary economics. Cheltnham, E. Elgar.

FURMAN, J. L.; PORTER, M. E. \& STERN, S. (2001), "The determinants of national innovative capacity". Trabalho apresentado no MIT Industrial Performance Seminar. Cambridge, 26 set.

GERSCHENKRON, A. (1962), Economic backwardness in historical perspective. Cambridge, Harvard University Press.

GOLDMAN SACHS. (2009), "The BRICs Nifty 50: The EM \& DM Winners". Goldman Sachs Global Economics, Commodities and Strategy Research, 4 nov.

GUIMARÂES, E. \& Ford, E. (1975), "Ciência e tecnologia nos planos de desenvolvimento: 1956-1973". Pesquisa e Planejamento Econômico. Rio de Janeiro, Ipea, vol. 5, 2 dez.

HIRSCHMAN, A. (1968), "The political economy of ISI in Latin America". The Quarterly Journal of Economics, 52 (1): 1-32.

HOBDAY, M. (1994), "Export-led technology development in the four dragons: the case of electronics". Development and Change, 25 (2): 333-361. (1995), Innovation in East Asia. Cheltenham, E. Elgar.

HU, M. C. \& MATHEWS, J. A. (2005), "Innovative capacity in East Asia". Research Policy, 34 (9): 1322-1349.
(2008), "China's national innovative capacity". Research Policy, 37: 1465-1479.

IBGE. (2007), "Pesquisa industrial de inovação tecnológica". Rio de Janeiro, IBGE.

KIM, L. (1997), "Imitation to innovation: the dynamics of Korea's technological learning". Boston, Harvard Business School Press.

KIM, M. J. \& MAH, J. S. (2009), "China's R\&D Policies and Technology-intensive industries". Journal of Contemporary Asia, 39 (2): 262-278.

LAM, A. (2010), "From 'ivory tower traditionalists' to 'entrepreneurial scientists'?". Social Studies of Science, forthcoming.

LEMOS, P. (2009), "Inovação e empreendedorismo científico e tecnológico: alguns aspectos da experiência da Inova e da Unicamp", in M. dos Santos, P. Toledo e R. Lotufo (eds.), Transferência de tecnologia: estratégias para a estruturação e gestão de Núcleos de Inovação Tecnológica. Campinas, SP, Komedi, pp. 307-320.

LUNDVALL, B. (1988), "Innovation as an interactive process: from user-producer interaction to the national system of innovation", in G. Dosi et al. (eds.), Technical change and economic theory, Londres, Pinter.

MACULAN, A. M. D. (1997), "From research to innovation: the Brazilian experience with business incubators", in Etzkowitz e Loet Leydesdorff (orgs.), Universities and the global knowledge economy: a triple helix university-industry-government relations. Londres/Nova York, Pinter.

MATHEWS, J. A. (2001), "National systems of economic learning: the case of technology diffusion management in East Asia". International Journal of Technology Management, 22 (5/6): 455-479.

MATHEWS, J. A. \& HU, M. C. (2007), "Enhancing the role of universities in building national innovative capacity in Asia: the case of Taiwan". World Development, 35 (6): 10051020.

MATTOS, P. \& ABDAL, A. (2010), "Estados Unidos: mudanças jurídico-institucionais e inovação", in G. Arbix, M. Salerno, D. Toledo, Z. Miranda e R. Alvarez (eds.), Inovação: estratégias de sete países, Brasília, ABDI, pp. 92-121. 
MOKYR, J. (2003), “Long-term economic growth and the history of technology", in P. Aghion e S. Durlauf (eds.), Handbook of economic growth, Amsterdan, North Holland, vol. 1B, pp. 1113-1180.

NSB - NATIONAL SCIENCE BOARD. (2010), "Science and engineering indicators 2010". Arlington, VA, National Science Foundation (NSB 10-01).

NELSON, R. (1996), The sources of economic growth. Cambridge, Harvard University Press. (2004), "The challenge of building an effective innovation system for catch-up". Oxford Development Studies, 32 (3): 365-374.

NELSON, R. \& SAMPAT, B. (2001), "Making sense of institutions as a factor shaping economic performance". Journal of Economic Behavior and Organization, 44 (1): 31-54.

NONAKA, I. \& TAKEUCHI, H. (1995), The knowledge creating company: how japanese companies create the dynamics of innovation. Nova York, Oxford University Press.

NORTH, D. (1990), Institutions, institutional change, and economic performance. Cambridge, Cambridge University Press.

OCAMPO, J. A. (2004), "La América Latina y la economía mundial en el largo siglo XX". El Trimestre Económico, LXXI (4): 725-786

PISANO, G. (2006), Science business: the promise, the reality, and the future of biotech. Cambridge, Harvard Business School Press.

PITCE. (2004), "Política Industrial, Tecnológica e de Comércio Exterior”. Disponível em <www. mdic.gov.br>.

PREBISCH, R. (1973), "Interpretación del proceso de desarrollo latinoamericano em 1949". Serie conmemorativa del XXV Aniversario de la Cepal, Santiagom Cepal.

ROMER, P. (1992), "Two strategies for economic development: using ideas and producing Ideas". Working Paper. Washington, D.C., Bird. (2001), "Post-scarcity prophet". Depoimento concedido a Ronald Bailey. Disponível em <reason.com/archives/2001/12/01/post-scarcity-prophet>.

Bank. (2005), "The arc of science". World
ROSENBERG, N. (1982), Inside the black box: technology and economics. Nova York, Cambridge University Press.

(1994), "Economic experiments", in , Exploring the black box, Cambridge, Cambridge University Press.

SALES, D. I. (2009), "Gestão de incubadora de empresas de base tecnológica: o caso Incamp", in M. dos Santos, P. Toledo e R. Lotufo (eds.), Transferência de tecnologia: estratégias para a estruturação e gestão de Núcleos de Inovação Tecnológica. Campinas, SP, Komedi, pp. 321-350.

SCHRANK, A. \& KURTZ, M. (2005), "Credit where credit is due: open economy industrial policy and export diversification in Latin America and the Caribbean”. Politics Society, 33 (4): 671-702.

SCHWARTZMAN, S. (2010), "Changing universities and academic outreach". Paper prepared to New Century Scholar's Program 2009-2010. Washington, DC, Fulbright Commission.

SHEEHAN, P. (2008), "Beyond industrialization: new approaches to development strategy based on the service sector". UNU-WIDER, Research Paper 60, maio.

STOKES, D. E. (1997), Pasteur's quadrant: basic science and technological innovation. Washington, DC, Brookings Institution Press.

SUZIGAN, W. \& FURTADO, J. (2006), "Política industrial e desenvolvimento". Revista de Economia Política, 26 (2): 163-185

TELES, J. (1985), Pela valorização da inteligência. Brasília, Editora Universidade de Brasília.

TORKOMIAN, A. L. (2009), "Panorama dos núcleos de inovação tecnológica no Brasil” in $\mathrm{M}$. dos Santos, P. Toledo e R. Lotufo (eds.), Transferência de tecnologia: estratégias para a estruturação e gestão de Núcleos de Inovação Tecnológica. Campinas, SP, Komedi, pp. 21-38.

VAIDYANATHAN, G. (2007), "Technology parks in a developing country: the case of India". Journal of Technology Transfer, 33: 285-299.

VERMULM, R. \& DE PAULA, T. (2006), “A política tecnológica no Brasil e a experiência internacional". São Paulo, Relatório do Iedi. 


\section{INOVAR PARA TRANSFORMAR A UNIVERSIDADE BRASILEIRA}

\section{Glauco Arbix e Flávia Consoni}

Palavras-chave: Universidade; Inovação; Modelo linear; Agência Inova; Núcleos de inovação tecnológica.

Qual o lugar das instituições de ensino superior no estímulo à geração e à difusão de inovações na economia e na sociedade? A universidade, no mundo todo, vive uma segunda revolução acadêmica. Ensino e pesquisa combinam-se para transferir conhecimento para a sociedade. Além de realçar experiências internacionais que explicitam resistências à mudança a partir da persistência do modelo linear de inovação, este artigo enfatiza o papel proativo que as universidades podem desempenhar nos processos de desenvolvimento. $\mathrm{O}$ artigo conclui com recomendaçóes para melhoria do sistema, necessárias para construção de uma estratégia baseada na inovação, que tem nas universidades peça essencial.

\section{INNOVATE TO TRANSFORM THE BRAZILIAN UNIVERSITY}

\section{Glauco Arbix and Flávia Consoni}

Keywords: University; Innovation; Linear model; Inova Agency; Technological innovation centers.

How can universities foster the generation and diffusion of innovation in the economy and society? Universities worldwide have experienced a second academic revolution. Teaching and research are both transferring knowledge to society. This article analyzes the proactive role that universities can play in the development process. The article makes some recommendations on how to effectively strengthen the national system of innovation anchored in innovative universities.

\section{INNOVER POUR TRANSFORMER L'UNIVERSITÉ BRÉSILENNE}

\section{Glauco Arbix et Flávia Consoni}

Mots-clés: Université; Innovation; Modèle linéaire; Agence Inova; Noyaux d'innovation technologique.

Quel est la place des institutions d'enseignement supérieur dans la stimulation de la génération et de la diffusion d'innovations dans l'économie et dans la société ? Dans le monde entier, l'université vit une seconde révolution académique. L'enseignement et la recherche se joignent pour transférer le savoir à la société. Cet article souligne non seulement les expériences internationales qui explicitent les résistances au changement à partir de la persistance du modèle linéaire d'innovation, mais met en avant le rôle proactif que les universités peuvent jouer dans les processus de développement. L'article se conclut par des recommandations pour l'amélioration du système, nécessaires à la construction d'une stratégie fondée sur l'innovation et qui a, dans les universités, son outil essentiel. 